\title{
Biology and Management of Dedifferentiated Liposarcoma: State of the Art and Perspectives
}

\author{
Jun Nishio $^{1, *}$, Shizuhide Nakayama ${ }^{1}$, Kazuki Nabeshima ${ }^{2}$ and Takuaki Yamamoto ${ }^{1}$ \\ 1 Department of Orthopaedic Surgery, Faculty of Medicine, Fukuoka University, 7-45-1 Nanakuma, Jonan-ku, \\ Fukuoka 814-0180, Japan; n.shizuhide@gmail.com (S.N.); yamamotot@fukuoka-u.ac.jp (T.Y.) \\ 2 Department of Pathology, Faculty of Medicine, Fukuoka University, 7-45-1 Nanakuma, Jonan-ku, \\ Fukuoka 814-0180, Japan; kaznabes@fukuoka-u.ac.jp \\ * Correspondence: jnishio@cis.fukuoka-u.ac.jp
}

check for updates

Citation: Nishio, J.; Nakayama, S.; Nabeshima, K.; Yamamoto, T. Biology and Management of Dedifferentiated Liposarcoma: State of the Art and Perspectives. J. Clin. Med. 2021, 10 , 3230. https://doi.org/10.3390/ jcm10153230

Academic Editor: Andrea Angelini

Received: 15 June 2021

Accepted: 21 July 2021

Published: 22 July 2021

Publisher's Note: MDPI stays neutral with regard to jurisdictional claims in published maps and institutional affiliations.

Copyright: (c) 2021 by the authors. Licensee MDPI, Basel, Switzerland. This article is an open access article distributed under the terms and conditions of the Creative Commons Attribution (CC BY) license (https:// creativecommons.org/licenses/by/ $4.0 /)$.

\begin{abstract}
Dedifferentiated liposarcoma (DDL) is defined as the transition from well-differentiated liposarcoma (WDL)/atypical lipomatous tumor (ALT) to non-lipogenic sarcoma, which arises mostly in the retroperitoneum and deep soft tissue of proximal extremities. It is characterized by a supernumerary ring and giant marker chromosomes, both of which contain amplified sequences of 12q13-15 including murine double minute 2 (MDM2) and cyclin-dependent kinase 4 (CDK4) cell cycle oncogenes. Detection of MDM2 (and/or CDK4) amplification serves to distinguish DDL from other undifferentiated sarcomas. Recently, CTDSP1/2-DNM3OS fusion genes have been identified in a subset of DDL. However, the genetic events associated with dedifferentiation of WDL/ALT remain to be clarified. The standard treatment for localized DDL is surgery, with or without radiotherapy. In advanced disease, the standard first-line therapy is an anthracycline-based regimen, with either single-agent anthracycline or anthracycline in combination with the alkylating agent ifosfamide. Unfortunately, this regimen has not necessarily led to a satisfactory clinical outcome. Recent advances in the understanding of the pathogenesis of DDL may allow for the development of more-effective innovative therapeutic strategies. This review provides an overview of the current knowledge on the clinical presentation, pathogenesis, histopathology and treatment of DDL.
\end{abstract}

Keywords: dedifferentiated liposarcoma; well-differentiated liposarcoma; atypical lipomatous tumor; diagnosis; pathogenesis; treatment

\section{Introduction}

Adipocytic tumors are frequently encountered in routine practice. The 2020 World Health Organization Classification of Tumors of Soft Tissue and Bone recognizes five major liposarcoma subtypes: well-differentiated liposarcoma (WDL)/atypical lipomatous tumor (ALT); dedifferentiated liposarcoma (DDL); myxoid liposarcoma; pleomorphic liposarcoma; and myxoid pleomorphic liposarcoma [1]. DDL is characterized as a typically non-lipogenic sarcoma that is juxtaposed to WDL/ALT. Dedifferentiation occurs in up to $10 \%$ of WDL/ALT cases [2]. The incidence of DDL is less than 0.1 per $1,000,000$ each year [3]. DDL genetically overlaps with WDL/ALT; both entities are associated with high level amplifications of murine double minute 2 (MDM2) and cyclin-dependent kinase 4 (CDK4) cell cycle oncogenes within 12q13-15. DDL also shows recurrent amplifications of 1p32 and 6q23 [2]. Recently, novel fusion genes involving DNM3 opposite strand/antisense RNA (DNM3OS) have been identified in a subset of DDL [3]. Surgery remains the mainstay of treatment for localized DDL. Systemic treatment with chemotherapy and molecular targeted agents is one of the main therapeutic modalities in patients with advanced or metastatic disease. In this article, we review the key clinical, histopathological and genomic characteristics of DDL, summarize the current management and provide an overview of the ongoing research of novel therapeutic strategies. 


\section{Clinical Characteristics}

DDL presents most frequently in middle-aged and older adults (peak incidence in the sixth to seventh decades). It is a rare neoplasm in children and young adults [4]. There is a no gender predilection. Retroperitoneum is the most common location and DDL is the most frequent retroperitoneal sarcoma. DDL can also occur in the extremities, spermatic cord, trunk (including mediastinum and thorax) and head and neck [1]. In our experience, occurrence in the superficial soft tissue is extremely rare.

DDL usually presents as a large painless mass, often with a history of several years of slow enlargement [5]. In the retroperitoneum, it may be detected incidentally during radiological imaging. Presenting symptoms are typically related to the location of origin. Dedifferentiation is likely a time-dependent phenomenon and up to $90 \%$ of DDL cases arise de novo [1]. In the remaining $10 \%$ of cases, DDL develops as a dedifferentiated recurrence of a previous WDL/ALT.

Unlike WDL/ALT, DDL is a high-grade and aggressive disease, with a local recurrence rate of approximately $40 \%$, metastatic rate of $15-30 \%$ and overall mortality rate of $28 \%[6,7]$. The most important prognostic factor for DDL is anatomical location. Actually, a few studies showed that the extremities were a favorable location for DDL compared with the retroperitoneum $[8,9]$.

\section{Imaging Features \\ 3.1. MRI}

Magnetic resonance imaging (MRI) is the preferred modality for evaluating soft tissue lesions and is helpful in demonstrating the fatty nature of the tumor. DDL represents a biphasic neoplasm, with one component being a WDL/ALT and the other a non-lipogenic sarcoma (Figure 1). The WDL/ALT component demonstrates high signal intensity on both T1- and T2-weighted images, consistent with a lipomatous tumor. The dedifferentiated component is usually larger than $3 \mathrm{~cm}$ [10] and typically shows a non-specific MR appearance with prolonged T1 and T2 relaxation times. Hemorrhage and necrosis may be seen within the high-grade dedifferentiated component. In our limited experience, gadolinium contrast enhancement of the dedifferentiated component is variable.
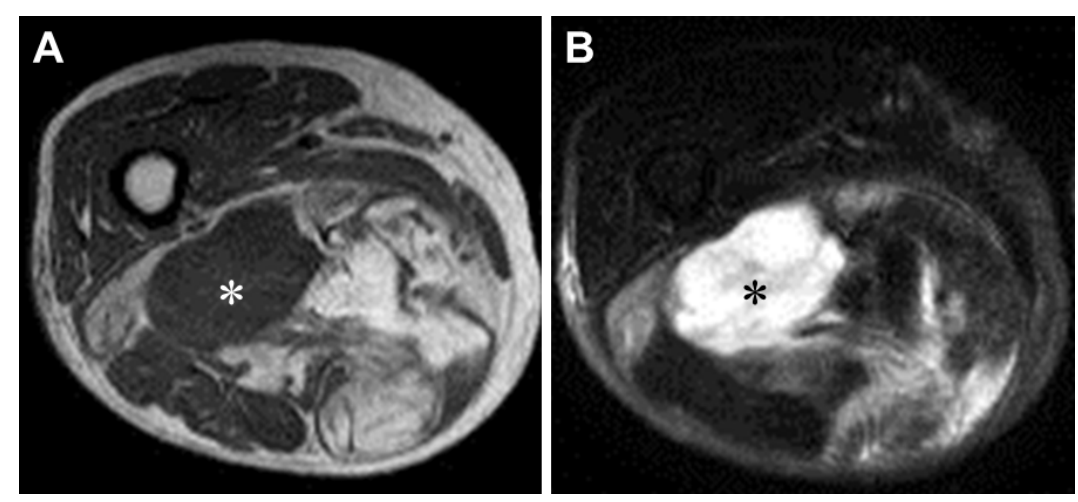

Figure 1. Magnetic resonance imaging of dedifferentiated liposarcoma in the right thigh of an 83year-old woman. Axial T1-weighted (A) and T2-weighted spectral presaturation with inversion recovery (B) sequences display a large soft tissue mass composed of non-lipomatous (white and black asterisks) and juxtaposed lipomatous components.

\subsection{F-FDG PET/CT}

Positron emission tomography (PET) is the gold standard in metabolic imaging. The radionuclide most commonly used for PET is fluorodeoxyglucose (FDG). High-grade malignancies tend to have higher rates of glycolysis and FDG uptake than those of intermediate malignancies and benign lesions. The dedifferentiated component displays high FDG uptake, whereas the WDL/ALT component shows almost no FDG uptake [8]. It is recognized that PET/computed tomography (CT) would be useful for identifying 
the presence of dedifferentiation within the tumor. Moreover, PET/CT can be helpful in guiding the location for biopsy in this heterogeneous tumor [11,12].

\section{Pathogenesis}

Karyotypes and quantitative genomic profiles of DDL are often more complex than those of WDL/ALT. DDL is cytogenetically characterized by a supernumerary ring and giant marker chromosomes [1,13-15]. These rings and giant markers contain amplified sequences of 12q13-15 and other co-amplified chromosomal regions (Figure 2). The 12q1315 region includes a number of genes such as MDM2, CDK4, high mobility group AT-hook 2 (HMGA2), tetraspanin 31 (TSPAN31), YEATS domain containing 4 (YEATS4), carboxypeptidase $M(C P M)$ and solute carrier family 35 member E3 (SLC35E3) [3,5]. MDM2 is the main driver gene with the 12q amplicon. MDM2 binds to p53 and negatively regulates it by preventing nuclear translocation and transcription and by promoting its degradation via an E3 ubiquitin ligase [16]. CDK4 encodes a 33-kD protein that is a key factor in the regulation of the G1-S translation of the cell cycle. Accumulation of the CDK4-CCDN1 complex leads to phosphorylation of the retinoblastoma (RB) protein [14]. In current practice, immunohistochemistry for MDM2 and CDK4 can be helpful to screen for 12q13-15 amplification. $H M G A 2$ encodes a protein in the nonhistone chromosomal high-mobility group (HMG) protein family that contains DNA-binding domains and can act as a transcriptional regulating factor. HMGA2 and TSPAN31 are commonly coamplified with $M D M 2$, implicating a critical role in the development of DDL $[17,18]$. YEATS4 encodes a putative transcription factor required for physiologic suppression of p53 function and its knockdown reduces DDL cell proliferation [19]. CPM belongs to the family of the carboxypeptidases and its knockdown results in the inhibition of DDL cell growth, migration and invasion [20]. YEATS4 and CPM, frequently coamplified with $M D M 2$, are known to be involved in the dedifferentiation process [21]. SLC35E3 is a protein coding gene and the simultaneous gain of MDM2, CPM and SLC35E3 is likely a crucial step during the development of DDL [3].

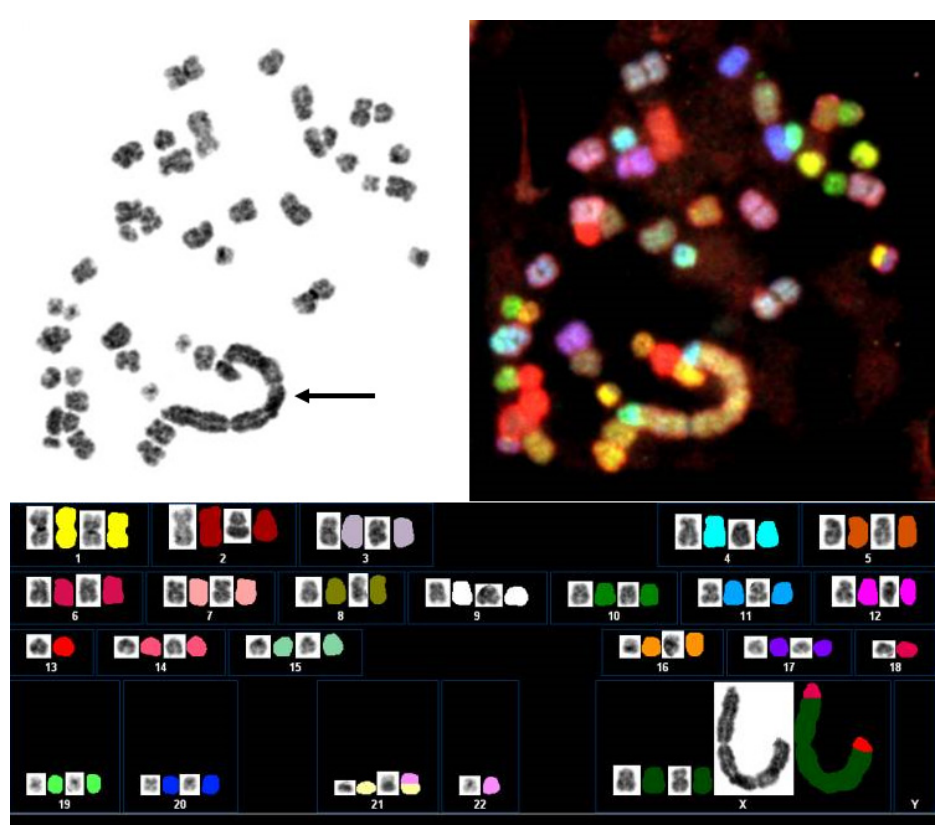

Figure 2. Giant marker chromosome in dedifferentiated liposarcoma. Spectral karyotyping demonstrates that the giant marker (arrow) is mainly composed of material from the $\mathrm{X}$ chromosome.

In addition to the 12q13-15 amplification, high-level amplifications of $1 \mathrm{p} 32$ and $6 \mathrm{q} 23$ are found in DDL and are associated with a worse prognosis [22]. It is of great interest that coamplifications of $1 \mathrm{p} 32$ and $6 \mathrm{q} 23$ are mutually exclusive and never seen in WDL. Jun proto-oncogene (JUN) and mitogen-activated protein kinase kinase kinase 5 (MAP3K5) are upregulated through amplifications in 1p32 and 6q23, respectively [22]. JUN encodes 
part of the activator protein transcription factor (AP-1) complex involved in cell proliferation, transformation and apoptosis and inhibits peroxisome proliferator-activated receptor gamma (PPAR $\gamma$ ), a key mediator of adipocytic differentiation [14,23]. MAP3K5 encodes a MAP3 kinase involved in the Jun N-terminal kinase (JNK) signaling pathway [14,24]. MAP3K5 amplification activates JNK ultimately leading to JUN activation and PPAR $\gamma$ inactivation. It is therefore suggested that amplifications of JUN and/or MAP3K5 may directly block adipocytic differentiation in DDL. Saâda-Bouzid et al. reported that CDK4 and JUN amplification were associated with a poor outcome. Moreover, receptor tyrosine kinase (RTK) genes are also amplified in DDL, including discoidin domain receptor tyrosine kinase 2 (DDR2), Erb-B2 receptor tyrosine kinase 3 (ERBB3), neurotrophic tyrosine receptor kinase 1 (NTRAK1), fibroblast growth factor receptor 1 (FGFR3) and ROS Proto-Oncogene 1 (ROS1) [25]. Asano et al. suggested that amplification of these RTK genes is probably involved in DDL progression [25]. Based on these findings, we speculate that tyrosine kinase inhibitors (TKIs) may be an effective therapeutic option for DDL patients with RTK gene amplification. On the other hand, somatic point mutations are uncommon in DDL [26].

A recent study on the integrated exome and RNA sequencing of DDL demonstrated CTD small phosphatase 1 (CTDSP1)-DNM3OS and CTD small phosphatase 2 (CTDSP2)DNM3OS as recurrent fusion genes [3]. CTDSP1 and CTDSP2 encode the C-terminal domain small phosphatases 1 and 2 and knockdown of CTDSP2 reduces DDL cell proliferation [20]. DNM3OS is located at 1q24.3 and encodes the microRNA cluster miR199a 214 [27]. Interestingly, DDL with these fusion genes showed the significant upregulation of DNM3OS and the gain of 1q24.3 were associated with poor progression-free survival (PFS) [3]. These findings suggest that upregulation of DNM3OS may contribute to DDL progression.

\section{Histopathology}

The histological hallmark of DDL is transition from WDL/ALT to non-lipogenic sarcoma [1]. However, it may be difficult to identify the WDL/ALT component in some cases. In current practice, fluorescence in situ hybridization (FISH) for the assessment of MDM2 amplification status can serve as a useful diagnostic adjunct for DDL.

Grossly, DDL usually appears as a large $(>10 \mathrm{~cm})$ multinodular yellow mass containing a discrete, solid, often freshy non-lipomatous area [1]. The cut surface is variable, ranging from gray-white to tan (Figure 3). Necrosis or hemorrhage may be seen within the dedifferentiated area.

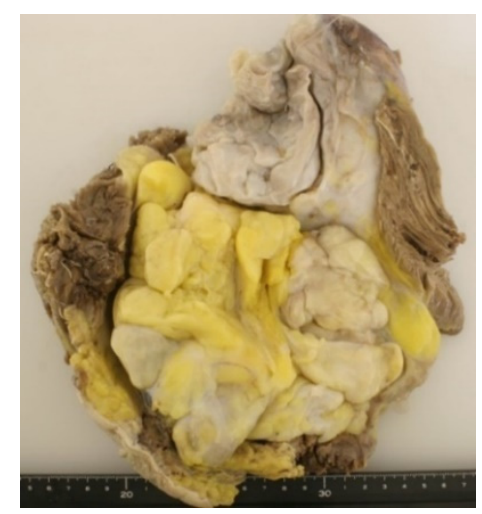

Figure 3. Cut surface showing a multilobulated appearance with gray-white and yellow areas.

Histologically, DDL usually show an abrupt transition between well-differentiated and dedifferentiated areas (Figure 4A). Well-dedifferentiated areas consist of mature fat cells with a significant variation in size and atypical, hyperchromatic stromal spindle cells. A varying number of monovacuolated or multivacuolated lipoblasts may be seen (Figure 4B). The extent of dedifferentiation is variable. Dedifferentiated areas exhibit a wide morphological spectrum but most frequently resemble undifferentiated pleomorphic 
sarcoma or high-grade myxofibrosarcoma (Figure 4C). The mitotic activity is variable and usually lower than that seen in other high-grade sarcomas. The concept of low-grade dedifferentiation is now widely recognized [6]. Low-grade dedifferentiation is characterized by the presence of bland fibroblast-like spindle cells with mild nuclear atypia and low mitotic activity [1]. In approximately $5-10 \%$ of cases, DDL undergoes heterogeneous differentiation [1]. The most frequent lines of dedifferentiation include myogenic, osteosarcomatous or chondrosarcomatous elements [6,28-30]. Myogenic dedifferentiation encompasses rhabdomyosarcomatous or leiomyosarcomatous elements. It is of interest that myogenic dedifferentiation, particularly with rhabdomyosarcomatous elements, is associated with a significantly worse outcome [28,29]. Rarely, a peculiar neural-like or meningothelial-like whirling pattern has been described in association with metaplastic ossification [31,32]. It is now recognized that most neoplasms previously diagnosed as inflammatory malignant fibrous histiocytoma or myxofibrosarcoma in the retroperitoneum represent DDL [7].

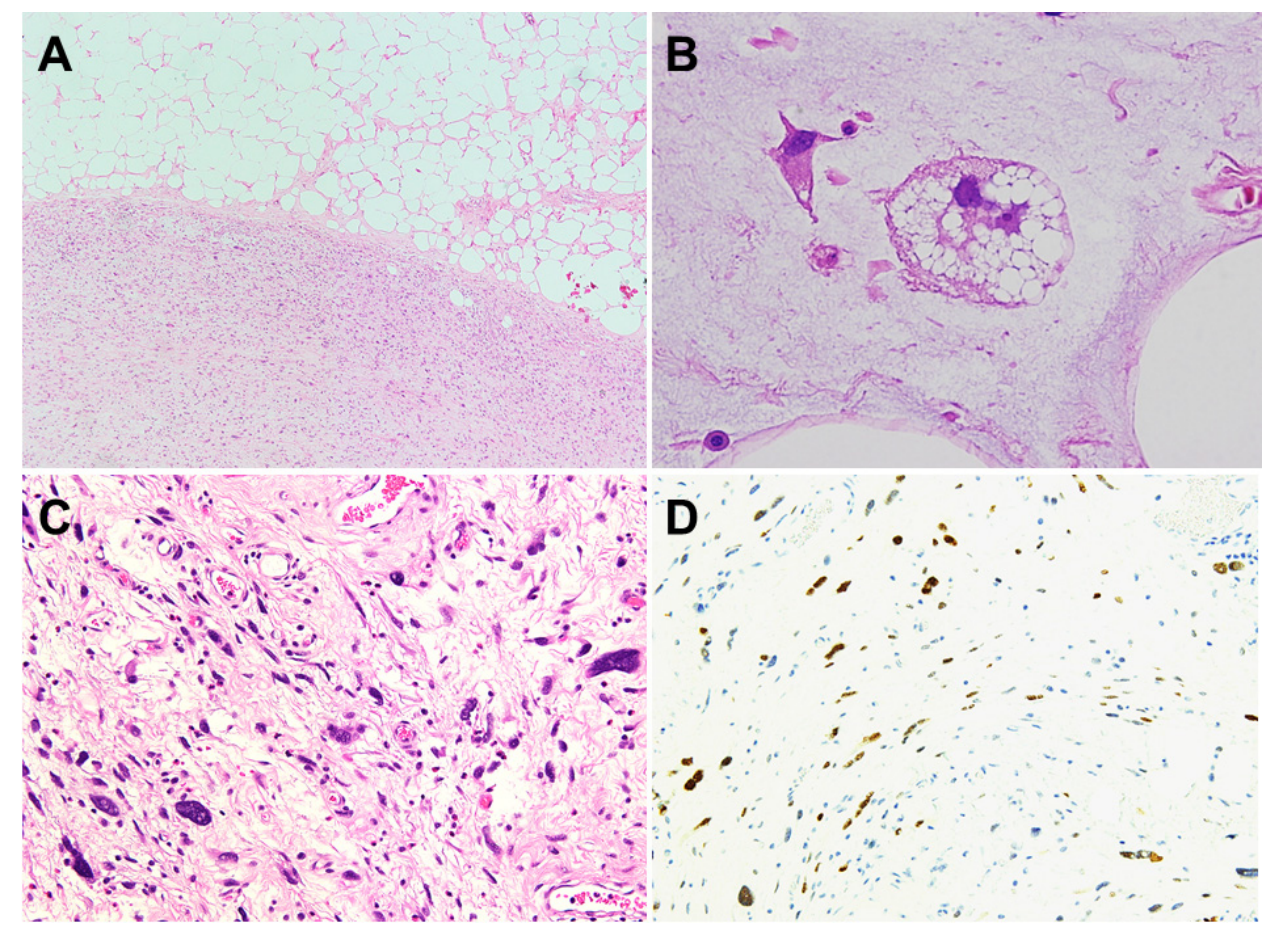

Figure 4. Histopathology of dedifferentiated liposarcoma. (A) Abrupt transition from welldifferentiated liposarcoma (WDL)/atypical lipomatous tumor (ALT) to high-grade non-lipogenic sarcoma is seen. (B) Multivacuolated lipoblast can be seen in the WDL/ALT area. (C) The dedifferentiated component consists of atypical spindle cells, round to polygonal cells and bizarre giant cells, resembling myxofibrosarcoma. (D) MDM2 expression in the dedifferentiated area.

The only reliable marker is the consistent nuclear reactivity of MDM2 (Figure 4D) and CDK4 [33]. In our experience, MDM2 and CDK4 expression is usually prominent in the dedifferentiated area compared to the WDL/ALT area. In the differential diagnosis of DDL, p16 had good sensitivity (94.4\%) but lower specificity (70\%) [34]. Although the use of p16 as a single immunohistochemical marker is limited due to its specificity, the combination of MDM2, CDK4 and p16 may be helpful in distinguishing DDL from other adipocytic neoplasms including pleomorphic liposarcoma [35]. DDL can exhibit variable expression of CD34 [36]. The S100 protein is absent in non-lipogenic areas of DDL.

In our experience, FISH is a useful adjunct in the diagnosis of DDL, especially when a corresponding WDL/ALT component is absent or obscure (Figure 5). There are several studies that evaluated the utility of MDM2 amplification in DDL. Weaver et al. reported $100 \%$ sensitivity and specificity for MDM2 amplification in distinguishing between benign 
lipomatous tumors and DDL [37]. Kimura et al. showed 100\% sensitivity and $95 \%$ specificity for MDM2 amplification in distinguishing DDL from other spindle and pleomorphic sarcomas [38]. The detection of CDK4 amplification by FISH is also helpful for distinguishing DDL from its histological mimics in the appropriate clinical context $[14,15,39]$. There are several studies that investigated the prognostic significance of these molecular alterations in DDL. Italiano et al. demonstrated that DDL with MDM2 amplification but no CDK4 amplification had a favorable prognosis [40]. Jour et al. reported that MDM2 amplification level was not a significant prognostic factor [41]. In that study, the authors suggested that Fédération Nationale des Centres de Lutte Contre le Cancer (FNCLCC) grading of DDL may predict a greater risk of local recurrence in FNCLCC grade 3 tumors. In contrast, Ricciotti et al. found that high MDM2 and CDK4 amplification levels (>38 and $>30$ copies, respectively) were associated with worse disease-free survival and diseasespecific survival [42]. Similarly, Lee et al. showed that high-level amplification of CDK4 was a poor prognostic marker [43].

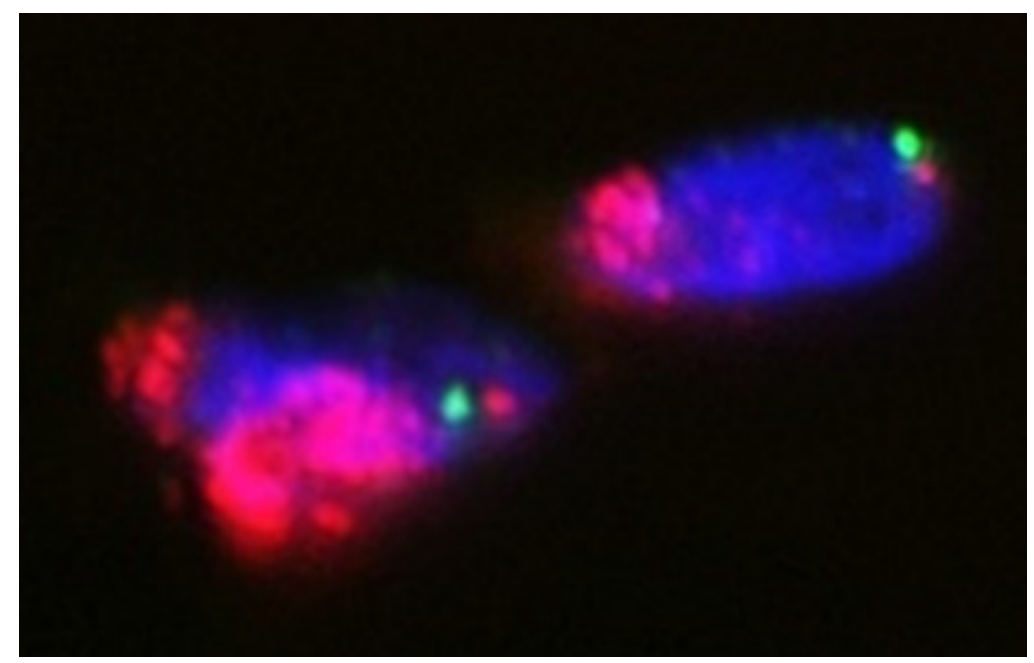

Figure 5. Interphase fluorescence in situ hybridization analysis using probes for MDM2 (red signals) and centromere of chromosome 12 (green signals) showing high-level amplification of MDM2.

\section{Management}

\subsection{Localized Disease}

Wide resection is the standard treatment for local disease. Resection with R0 margin is achievable for DDL located in the extremities but is more challenging for retroperitoneal tumors. In surgical practice, selection of which procedure is suitable for an individual patient must be based on tumor location, size, stage, relationship with surrounding neurovascular and bone elements and functional and cosmetic requirements.

Although some authors described improved local control associated with the use of radiation therapy (RT) in addition to surgery [44-46], a recent phase 3, randomized European Organization for Research and Treatment of Cancer (EORTC)-62092 trial showed that preoperative RT should not be considered as standard of care for primary retroperitoneal DDL [47]. On the other hand, the utility of RT for local control of primary extremity DDL remains unclear $[8,9]$ and there is controversy regarding its optimal timing. We now use RT when the resection proves $\mathrm{R} 1 / \mathrm{R} 2$ in extremity tumors close to major nerves and vessels.

\subsection{Advanced Disease}

The development of unresectable local and/or metastatic DDL is associated with a poor prognosis. In this section, we summarize an update of the current management of advanced DDL and highlight ongoing and future research. 


\subsubsection{Anthracycline-Based Therapy}

As with other soft tissue sarcoma (STS) subtypes, anthracycline-based therapy is a standard first-line treatment for advanced DDL [48,49]. Recent randomized phase 3 trials failed to demonstrate an improvement in overall survival (OS) with the addition of ifosfamide or other types of alkylator agents to doxorubicin in patients with metastatic STS [50-52]. In the EORTC-62012 phase 3 trial, post hoc subgroup analysis showed no improvement in objective response rate (ORR) or OS in patients with liposarcoma treated with combination therapy with doxorubicin and ifosfamide compared to doxorubicin alone [53]. In this trial, it was not specified how many had DDL.

There are several retrospective studies regarding the role of anthracycline-based treatment in patients with advanced DDL [54-56]. In the largest multi-institutional study, of the 208 patients, $171(82 \%)$ had DDL. Approximately $82 \%$ of patients received anthracyclinebased therapy. Among 167 evaluable patients, objective response (OR) was observed in 21 patients (12\%). Median PFS was 4.6 months and median OS was 15.2 months [55]. The largest single-center study of 82 patients with DDL treated with first-line chemotherapy showed that median PFS in the advanced setting was 4 months and median OS from the start of chemotherapy was 29 months. Among 51 evaluable patients treated in unresectable/metastatic setting, OR was observed in 10 patients (20\%) [56]. Taken together, it is reasonable to recommend that anthracycline-based regimens can be considered as a front-line treatment for advanced DDL.

\subsubsection{Pazopanib}

Pazopanib is an oral multi-target TKI with anti-angiogenic and antitumorigenic properties and has been approved in multiple countries as a second or later line treatment for patients with advanced STS. A single-arm phase 2 trial revealed that pazopanib was inactive in the liposarcoma subgroup [57]. In this EORTC-62043 trial, only $3(17.6 \%)$ of 17 patients met the criteria for a positive response. A subsequent randomized double-blind multicenter phase 3 trial excluded liposarcomas based on the EORTC-62043 data [58]. However, following a centralized histopathological review, 5 (26.3\%) of the 19 patients with liposarcoma had a progression-free rate (PFR) at 12 weeks, which would have met the threshold for further investigation in this study [57]. In recent years, a prospective single-arm multicenter phase 2 trial was performed to support the efficacy of pazopanib for advanced liposarcoma [59]. In this NCT01506596 trial, of the 41 patients, 27 (65.9\%) had DDL. Median PFS for patients with DDL was 6.24 months. Median OS among all patients was 12.6 months. Another phase 2 clinical trial (NCT01692496) was designed to assess PFS at 12 weeks and was achieved in $43.2 \%$ of patients with advanced WDL/DDL [60]. In the WDL/DDL subgroup, median PFS and OS were 3.5 and 16.4 months, respectively. In a randomized phase 2 clinical trial (EPAZ) assigned to doxorubicin or pazopanib, for both PFS and OS, pazopanib showed non-inferiority compared to doxorubicin with similar quality of life measure outcome [61]. These phase 2 studies suggested that the use of pazopanib in treating advanced DDL may show promise [59-61]. More recently, Suehara et al. indicated that pazopanib is possibly a favorable clinical option in advanced STS with GLI Family Zinc Finger 1 (GLI) amplification such as DDL [62]. The role of pazopanib in advanced DDL remains unclear and requires further investigation in a phase 3 study.

Other multi-target TKIs such as sunitinib [63], regorafenib [64] and anlotinib [65] have also been investigated in phase 2 trials in advanced STS including liposarcoma. None are currently licensed for use in liposarcoma.

\subsubsection{Eribulin}

Eribulin, a non-taxane microtubule dynamics inhibitor, is currently licensed for use in patients with unresectable or metastatic liposarcoma who received a prior anthracyclinebased regimen. The approval was based on results from a randomized open-label multicenter phase 3 trial enrolling 452 patients with advanced liposarcoma or leiomyosarcoma [66]. In this E7389-G000-309 trial, OS was significantly improved in the eribulin arm compared 
to the dacarbazine arm (median OS, 13.5 versus 11.5 months; hazard ratio (HR) $0.77 ; 95 \%$ confidence interval (CI) $0.62-0.95 ; p=0.0169)$, despite there being no significant difference between the two arms in median PFS. Subsequently, a subgroup analysis by histological subtype, using data from the E7389-G000-309 study, indicated that among the total of 65 patients with DDL, median OS was 18.0 months in those receiving eribulin compared to 8.1 months in those receiving dacarbazine [67]. Therefore, eribulin can be expected to improve OS in patients with advanced DDL.

\subsubsection{Trabectedin}

Trabectedin, a marine-derived drug that binds to the minor groove of DNA, has also been approved by the United States Food and Drug Administration (FDA) and European Medicines Agency (EMA) for treatment of patients with unresectable or metastatic liposarcoma who received a prior anthracycline-based regimen. The approval was based on results from a randomized open-label multicenter phase 3 trial enrolling 518 patients with advanced liposarcoma or leiomyosarcoma [68]. In this ET743-SAR-3007 trial, PFS was significantly improved in the trabectedin arm compared to the dacarbazine arm (median PFS, 4.2 versus 1.5 months; HR $0.55 ; 95 \%$ CI $0.44-0.70 ; p<0.001)$. However, the final OS analysis demonstrated no significant improvement in OS of trabectedin over dacarbazine [69]. A subgroup analysis by histological subtype, using data from the ET743-SAR-3007 study, showed that among the total of 70 patients with DDL, median PFS was 2.2 months in those receiving trabectedin compared to 1.9 months in those receiving dacarbazine [68]. In the retrospective case series, Fabbroni et al. suggested that trabectedin may be more active against WDL/low-grade DDL than in high-grade DDL [70].

\subsubsection{Gemcitabine and Docetaxel}

The combination of gemcitabine and docetaxel has activity in patients with advanced STS [71]. A subgroup analysis by histological subtype, using data from a randomized openlabel phase 2 study (NCT00142571), revealed that the use of gemcitabine and docetaxel or gemcitabine alone demonstrated stable disease (SD) in $9(75 \%)$ of the 12 patients with advanced WDL/DDL, although most responses were for less 24 weeks [72]. A randomized controlled phase 3 trail (GeDDiS) was performed to compare the efficacy of gemcitabine and docetaxel versus doxorubicin in the first-line setting for advanced STS [73]. There was no significant difference between the two arms in PFS and OS, which contained eight and five patients with DDL, respectively. The precise role of gemcitabine and docetaxel in advanced DDL remains to be defined, particularly the potential for combination therapy.

\subsubsection{MDM2-Thargeted Therapy}

MDM2 is a critical component of DDL tumorigenesis [74]. An exploratory proof-ofmechanism study demonstrated adequate safety, tolerability, p53 activation, antiproliferative activity and preliminary antitumor efficacy of the investigational MDM2 inhibitor RG7112 in patients with operable MDM2-amplified WDL/DDL [75]. A first-in-human phase 1 trial (NCT01636479) of SAR405838, an oral spirooxindole inhibitor of MDM2, showed no OR; however, SD was observed in 22 (71\%) of the 31 patients with DDL [76]. Progression-free response (PFR) at 3 months was met by $32 \%$ of patients [76]. Another phase 1 trial of MK-8242, a small molecule inhibitor of MDM2, showed that ORR was 11.1\% in the 27 patients with advanced WDL/DDL and median PFS was 5.5 months in the 16 patients with advanced DDL [77].

Additional MDM2 inhibitors of several other classes are under ongoing investigation, including milademetan (DS-3032b), idasanutlin (RG7338), CPM097, ALRN-6924 and JNJ26854105. Updated results from a phase 1 study (NCT01877382) of milademetan enrolling 40 patients with WDL/DDL reported preliminary clinical activity and an acceptable safety profile [78]. A partial response (PR) was seen in one patient with DDL [78]. Although TP53 mutations appear in circulating cell-free DNA of patients with DDL during treatment 
with the MDM2 inhibitor [79], targeting MDM2 is a promising treatment strategy for this disease.

\subsubsection{CDK4-Thageted Therapy}

CDK4 is amplified in over $90 \%$ of DDL [49]. Three CDK4/ 6 inhibitors are currently approved in clinical practice, namely: palbociclib, ribociclib and abemaciclib. Palbociclib, a potent oral inhibitor of CDK4 and CDK6, induces cell cycle arrest in CDK4-amplified WDL/DDL cells [19]. In a non-randomized open-label phase 2 study (NCT01209598), of the 60 patients, $47(78 \%)$ had DDL and received palbociclib at $125 \mathrm{mg}$ daily for 21 days in 28-day cycles [80]. Median PFS was 17.9 weeks, with overall PFS at 12 weeks of $57.2 \%$ and a manageable toxicity profile. One patient achieved a complete response (CR) [80].

Several other CDK4/ 6 inhibitors are under ongoing investigation, including ribociclib [81] and abemaciclib [82]. In an open-label phase 1 study (NCT01237236) of single-agent ribociclib in liposarcoma, no OR was observed ( 0 of 39 evaluable patients), although SD surpassing 6 months was seen in 6 patients (15\%) [81]. In a single-arm phase 2 study (NCT02846987), 30 patients with advanced DDL (29 evaluable for response) were enrolled to receive oral abemaciclib at $200 \mathrm{mg}$ twice daily without interruption. Median PFS was 30.4 weeks, with overall PFS at 12 weeks of $76 \%$ and a manageable toxicity profile. There was one PR and a further 3 patients had a reduction of more than $10 \%$ in tumor size by the Response Evaluation Criteria in Solid Tumors (RECIST) guidelines (version 1.1) [82].

The palbociclib and RG7388 (MDM2 inhibitor) combination in DDL led to an increased rate of apoptosis, recued tumor growth and had a significant increase in median PFS compared to a single agent alone [83]. A phase 1b study (NCT02343172) assessing the safety and efficacy of HDM201 (MDM2 inhibitor) in combination with LEE001 (ribociclib) is currently ongoing in patients with advanced DDL.

\subsubsection{Exportin 1 (XPO1) Inhibitor}

Nuclear export is a rational target in DDL [49]. XPO1 mediates nuclear export of multiple tumor suppressor and growth regulatory proteins. XPO1 is highly expressed in different histological subtypes of liposarcoma including DDL [84]. Selinexor, an oral selective inhibitor of XPO1, significantly inhibited cellular proliferation and induced cell cycle arrest and apoptosis of DDL both in vitro and in vivo [84]. Recently, Zuco et al. demonstrated that antitumor activity of selinexor was higher than doxorubicin in DDL patient-derived xenografts and cell lines [85]. In a phase 1b clinical trial (NCT01896505), although no OR was observed, selinexor demonstrated antitumor activity in patients with advanced $\mathrm{DDL}$, showing a reduction in the target lesion size from baseline in $6(40 \%)$ of 15 patients, with $47 \%$ of patients experiencing a best response of SD for at least 4 months [86]. A subsequent randomized double-blinded placebo-controlled multicenter phase 2/3 (SEAL) study (NCT02606461) was initiated to assess the efficacy, safety and health-related quality of life (HRQoL) of patients with advanced DDL treated with either selinexor or placebo. This phase 3 SEAL study demonstrated enhanced clinical activity and a manageable safety profile in patients with DDL compared to placebo [87]. Median PFS was 2.83 months in the selinexor arm versus 2.07 months in the placebo arm (HR $0.70 ; p=0.0228)$. There was no significant difference between the two arms in OS [87]. Most recently, Gounder et al. reported that pain scores worsened in the placebo arm compared to the selinexor arm across all postbaseline visits, although some visits (day 43 and 85 ) were not statistically significant [88].

\subsubsection{Immunotherapy}

The major targets of FDA-approved immunotherapeutic antibodies are programmed cell death protein-1 (PD-1), its ligand programmed cell death ligand-1 (PD-L1) and cytotoxic T lymphocyte-associated antigen-4 (CTLA-4) [89]. PD-1 is normally expressed on the surface of activated $\mathrm{T}$ cells and suppresses unwanted or excessive immune responses. PD-L1 is widely expressed in a variety of cells. CTLA-4 is a protein receptor expressed on 
the T lymphocyte surface that plays a crucial role during T cell activation. The PD-1/PD-L1 interaction is a major pathway hijacked by tumors to suppress immune control. Several studies have assessed the expression of PD-L1 in DDL [90-92]. PD-L1 positive expression $(\geq 1 \%)$ was identified in $21.9 \%(7 / 32)$ of the DDL cases [90]. The $\geq 1 \%$ PD-L1 expression group demonstrated a significantly worse recurrence-free survival (RFS) ( $p=0.027$ ) and OS $(p=0.017)$ compared to the no PD-L1 expression group [90]. Miyake et al. also reported that DDL showed a significantly higher level of PD-L1 expression $(p=0.02)$ compared to other STSs [92]. These studies suggest the possibility of this pathway-targeted immunotherapy for advanced DDL.

Pembrolizumab and nivolumab are the two most representative PD-1 inhibitors. In a single-arm open-label multicenter phase 2 (SARC028) trial (NCT02301039), pembrolizumab demonstrated promising activity in patients with advanced DDL [93]. Among 10 evaluable patients with DDL, $2(20 \%)$ had PR and $4(40 \%)$ had SD. Median PFS was 25 weeks and PFS rate was $60 \%$ at 12 weeks [93]. The promising clinical results of the SARC028 study led to the enrollment of an expansion cohort consisting of an additional $30 \mathrm{DDL} /$ pleomorphic liposarcoma patients. In the liposarcoma cohort, ORR was $10 \%$ (4 of 39 patients with PR) and PFS rate was $44 \%$ at 12 weeks. Median PFS was 2 months and median OS was 13 months [94]. In a randomized open-label non-comparative multicenter phase 2 (Alliance A091401) trial (NCT02500797), patients with advanced/metastatic sarcoma received either nivolumab alone or nivolumab in combination with ipilimumab (CTLA4 inhibitor) [95]. ORR was 5\% in the nivolumab monotherapy group and $16 \%$ in the combination group. Median PFS was 1.7 and 4.1 months, respectively. Median OS was 10.7 and 14.3 months, respectively [95]. The promising results of the Alliance A091401 study led to the enrollment of an expansion cohort consisting of an additional 24 DDL patients. In the DDL cohort, the primary end point of 6-month response rate was met with the combination nivolumab plus ipilimumab but not with nivolumab alone. ORR was 6.7\% in the nivolumab monotherapy group and $14.3 \%$ in the combination group. Median PFS was 4.6 and 5.5 months, respectively. Median OS was 8.1 and 13.1 months, respectively [96]. Additionally, a randomized phase 2 clinical trial (NCT03307616) evaluating the efficacy of neoadjuvant checkpoint blockade (nivolumab or nivolumab/ipilimumab) in patients with surgically resectable primary or recurrent retroperitoneal DDL is currently under way [97]. Preliminary results showed that median pathological response was $22.5 \%$ and median change in tumor size (radiological response) was $+9 \%$ in the DDL cohort [98].

The combination of immunotherapy and RT may have the potential to elicit a systemic immune response to improve long-term survival in patients with advanced DDL. A randomized controlled phase 2 (SU2C-SARC032) trial (NCT03092323) to evaluate the safety and efficacy of neoadjuvant pembrolizumab with concurrent RT and adjuvant pembrolizumab compared to neoadjuvant RT alone in patients with high-risk extremity STS including DDL is currently ongoing [99].

\section{Conclusions}

DDL typically arises in the retroperitoneum or proximal extremities of middle-aged and older adults and is defined as the transition from WDL/ALT to non-lipogenic sarcoma, either in the primary tumor or in a recurrence of WDL/ALT. It is cytogenetically characterized by a supernumerary ring and giant marker chromosomes. These rings and giant markers contain amplified sequences of 12q13-15 including MDM2 and CDK4. In addition, the CTDSP1/2-DNM3OS fusion genes have been identified in a subset of DDL. The detection of MDM2 (and/or CDK4) amplification by FISH is a useful ancillary tool in the diagnosis of DDL. Surgical resection is the mainstay of treatment for localized DDL, although the use of RT or systemic therapies in conjunction with surgery may be considered in very selected patients. Anthracycline-based therapy is a standard first-line treatment for advanced DDL. Eribulin and trabectedin are currently the two most promising and evidenced-based second-line treatment options for advanced DDL. Pazopanib is possibly a favorable clinical option in advanced GLI-amplified DDL. MDM2 and CDK4 inhibitors 
have shown some evidence of efficacy in advanced DDL. However, the precise role of these agents remains to be elucidated, particularly the potential for combination therapy. Several other promising agents are currently under investigation for the treatment of advanced DDL in phase 2/3 clinical trials, including XPO1 and PD-1 inhibitors. In the future, we expect that a wide range of treatment options will be available to patients with this disease.

Author Contributions: Conceptualization, J.N.; data curation, J.N.; writing-original draft preparation, J.N.; writing - review and editing, S.N., K.N. and T.Y. All authors have read and agreed to the published version of the manuscript.

Funding: This research was funded by the Japan Society for the Promotion of Science KAKENHI (21K09336) and the Ogata Foundation.

Conflicts of Interest: The authors declare no conflict of interest.

\section{References}

1. The WHO Classification of Tumors Editorial Board. WHO Classification of Tumours of Soft Tissue and Bone, 5th ed.; IARC Press: Lyon, France, 2020; pp. 36-48.

2. Nishio, J. Contributions of Cytogenetics and Molecular Cytogenetics to the Diagnosis of Adipocytic Tumors. J. Biomed. Biotechnol. 2011, 2011, 1-9. [CrossRef]

3. Hirata, M.; Asano, N.; Katayama, K.; Yoshida, A.; Tsuda, Y.; Sekimizu, M.; Mitani, S.; Kobayashi, E.; Komiyama, M.; Fujimoto, H.; et al. Integrated exome and RNA sequencing of dedifferentiated liposarcoma. Nat. Commun. 2019, 10, 1-12. [CrossRef] [PubMed]

4. Waters, R.; Horvai, A.; Greipp, P.; John, I.; Demicco, E.G.; Dickson, B.C.; Tanas, M.; Larsen, B.T.; Din, N.U.; Creytens, D.H.; et al. Atypical lipomatous tumour/well-differentiated liposarcoma and de-differentiated liposarcoma in patients aged $\leq 40$ years: A study of 116 patients. Histopathology 2019, 75, 833-842. [CrossRef] [PubMed]

5. Thway, K. Well-differentiated liposarcoma and dedifferentiated liposarcoma: An updated review. Semin. Diagn. Pathol. 2019, 36, 112-121. [CrossRef]

6. Henricks, W.H.; Chu, Y.C.; Goldblum, J.R.; Weiss, S.W. Dedifferentiated liposarcoma: A clinicopathological analysis of 155 cases with a proposal for an expanded definition of dedifferentiation. Am. J. Surg. Pathol. 1997, 21, 271-281. [CrossRef]

7. Thway, K.; Jones, R.L.; Noujaim, J.; Zaidi, S.; Miah, A.B.; Fisher, C. Dedifferentiated liposarcoma: Updates on morphology, genetics and therapeutic strategies. Adv. Anat. Pathol. 2016, 23, 30-40. [CrossRef] [PubMed]

8. Nakata, E.; Kunisada, T.; Hasei, J.; Nakahara, R.; Yanai, H.; Toji, T.; Inoue, H.; Ozaki, T. What are the results of localized dedifferentiated liposarcomas in the extremities? Clin. Orthop. Relat. Res. 2020, 478, 2550-2561. [CrossRef]

9. Okada, K.; Hasegawa, T.; Kawai, A.; Ogose, A.; Nishida, J.; Yanagisawa, M.; Morita, T.; Tajino, T.; Tsuchiya, T. Primary (de novo) dedifferentiated liposarcoma in the extremities: A multi-institution Tohoku Musculoskeletal Tumor Society study of 18 cases in northern Japan. Jpn. J. Clin. Oncol. 2011, 41, 1094-1100. [CrossRef]

10. Murphey, M.D.; Arcara, L.K.; Fanburg-Smith, J. From the archives of the AFIP: Imaging of musculoskeletal liposarcoma with radiologic-pathologic correlation. RadioGraphics 2005, 25, 1371-1395. [CrossRef]

11. Parkes, A.; Urquiola, E.; Bhosale, P.; Lin, H.; Watson, K.; Wang, W.-L.; Feig, B.; Torres, K.; Roland, C.L.; Conley, A.P.; et al. PET/CT Imaging as a Diagnostic Tool in Distinguishing Well-Differentiated versus Dedifferentiated Liposarcoma. Sarcoma 2020, 2020, 1-6. [CrossRef]

12. Baffour, F.I.; Wenger, D.E.; Broski, S.M. 18F-FDG PET/CT imaging features of lipomatous tumors. Am. J. Nucl. Med. Mol. Imaging 2020, 10, 74-82.

13. Nishio, J.; Iwasaki, H.; Ishiguro, M.; Ohjimi, Y.; Fujita, C.; Ikegami, H.; Ariyoshi, A.; Naito, M.; Kaneko, Y.; Kikuchi, M. Establishment of a novel human dedifferentiated liposarcoma cell line, FU-DDLS-1: Conventional and molecular cytogenetic characterization. Int. J. Oncol. 2003, 22, 535-542.

14. Nishio, J.; Aoki, M.; Nabeshima, K.; Iwasaki, H.; Naito, M. Cytogenetic and molecular cytogenetic findings in giant dedifferentiated liposarcoma of the thigh. Oncol. Lett 2012, 27, 764-768. [CrossRef]

15. Nishio, J.; Iwasaki, H.; Nabeshima, K.; Naito, M. Immunohistochemical, cytogenetic, and molecular cytogenetic characterization of both components of a dedifferentiated liposarcoma: Implications for histogenesis. Anticancer Res. 2015, 35, 345-350. [PubMed]

16. Sciot, R. MDM2 Amplified Sarcomas: A Literature Review. Diagnostics 2021, 11, 496. [CrossRef] [PubMed]

17. Creytens, D.; Van Gorp, J.; Speel, E.-J.; Ferdinande, L. Characterization of the 12q amplicons in lipomatous soft tissue tumors by multiplex ligation-dependent probe amplification-based copy number analysis. Anticancer. Res. 2015, 35, 1835-1842. [PubMed]

18. Italiano, A.; Bianchini, L.; Keslair, F.; Bonnafous, S.; Cardot-Leccia, N.; Coindre, J.-M.; Dumollard, J.-M.; Hofman, P.; Leroux, A.; Mainguené, C.; et al. HMGA2 is the partner of MDM2 in well-differentiated and dedifferentiated liposarcomas whereas CDK4 belongs to a distinct inconsistent amplicon. Int. J. Cancer 2008, 122, 2233-2241. [CrossRef] [PubMed]

19. Barretina, J.; Taylor, B.S.; Banerji, S.; Ramos, A.H.; Lagos-Quintana, M.; DeCarolis, P.L.; Shah, K.; Socci, N.D.; Weir, B.A.; Ho, A.; et al. Subtype-specific genomic alterations define new targets for soft-tissue sarcoma therapy. Nat. Genet. 2010, 42, 715-721. [CrossRef] 
20. Kanojia, D.; Nagata, Y.; Garg, M.; Lee, D.H.; Sato, A.; Yoshida, K.; Sato, Y.; Sanada, M.; Mayakonda, A.; Bartenhagen, C.; et al. Genomic landscape of liposarcoma. Oncotarget 2015, 6, 42429-42444. [CrossRef]

21. Lee, A.T.J.; Thway, K.; Huang, P.; Jones, R.L. Clinical and Molecular Spectrum of Liposarcoma. J. Clin. Oncol. 2018, 36, 151-159. [CrossRef]

22. Tap, W.D.; Eilber, F.C.; Ginther, C.; Dry, S.M.; Reese, N.; Barzan-Smith, K.; Chen, H.W.; Wu, H.; Eilber, F.R.; Slamon, D.J.; et al. Evaluation of well-differentiated/de-differentiated liposarcomas by high-resolution oligonucleotide array-based comparative genomic hybridization. Genes Chromosomes Cancer 2011, 50, 95-112. [CrossRef]

23. Mariani, O.; Brennetot, C.; Coindre, J.M.; Gruel, N.; Ganem, C.; Delattre, O.; Stern, M.H.; Aurias, A. JUN oncogene amplification and overexpression block adipocytic differentiation in highly aggressive sarcomas. Cancer Cell 2007, 11, 361-374. [CrossRef]

24. Chibon, F.; Mariani, O.; Derré, J.; Mairal, A.; Coindre, J.-M.; Guillou, L.; Sastre, X.; Pédeutour, F.; Aurias, A. ASK1(MAP3K5) as a potential therapeutic target in malignant fibrous histiocytomas with 12q14-q15 and 6q23 amplifications. Genes Chromosom. Cancer 2004, 40, 32-37. [CrossRef] [PubMed]

25. Asano, N.; Yoshida, A.; Mitani, S.; Kobayashi, E.; Shiotani, B.; Komiyama, M.; Fujimoto, H.; Chuman, H.; Morioka, H.; Matsumoto, M.; et al. Frequent amplification of receptor tyrosine kinase genes in welldifferentiated/dedifferentiated liposarcoma. Oncotarget 2017, 8, 12941-12952. [CrossRef] [PubMed]

26. Demicco, E.G. Molecular updates in adipocytic neoplasms. Semin. Diagn. Pathol. 2019, 36, 85-94. [CrossRef]

27. El Azzouzi, H.; Leptidis, S.; Dirkx, E.; Hoeks, J.; Van Bree, B.; Brand, K.; McClellan, E.A.; Poels, E.; Sluimer, J.C.; Van Den Hoogenhof, M.M.; et al. The hypoxia-inducible microRNA cluster miR-199a 214 targets myocardial PPAR $\gamma$ and impairs mitochondrial fatty acid oxidation. Cell Metab. 2013, 18, 341-354. [CrossRef]

28. Gronchi, A.; Collini, P.; Miceli, R.; Valeri, B.; Renne, S.L.; Dagrada, G.; Fiore, M.; Sanfilippo, R.; Barisella, M.; Colombo, C.; et al. Myogenic differentiation and histologic grading are major prognostic determinants in retroperitoneal liposarcoma. Am. J. Surg. Pathol. 2015, 39, 383-393. [CrossRef]

29. Kurzawa, P.; Mullen, J.T.; Chen, Y.L.; Johnstone, S.E.; Deshpande, V.; Chebib, I.; Nielsen, G.P. Prognostic Value of Myogenic differentiation in dedifferentiated liposarcoma. Am. J. Surg. Pathol. 2020, 44, 799-804. [CrossRef] [PubMed]

30. Yoon, R.S.; Benevenia, J.; Beebe, K.S.; Hameed, M. Dedifferentiated liposarcoma of the thigh with chondrosarocomatous dedifferentiated component. Am. J. Orthop. 2010, 39, E114-E118. [PubMed]

31. Nascimento, A.G.; Kurtin, P.J.; Guillou, L.; Fletcher, C.D. Dedifferentiated liposarcoma: A report of nine cases with a peculiar neurallike whorling pattern associated with metaplastic bone formation. Am. J. Surg. Pathol. 1998, 22, 945-955. [CrossRef]

32. Fanburg-Smith, J.C.; Miettinen, M. Liposarcoma with meningothelial-like whorls: A study of 17 cases of a distinctive histological pattern associated with dedifferentiated liposarcoma. Histopathology 1998, 33, 414-424. [CrossRef] [PubMed]

33. Binh, M.B.; Sastre-Garau, X.; Guillou, L.; De Pinieux, G.; Terrier, P.; Lagacé, R.; Aurias, A.; Hostein, I.; Coindre, J.M. MDM2 and CDK4 immunostainings are useful adjuncts in diagnosing well-differentiated and dedifferentiated liposarcoma subtypes: A comparative analysis of 559 soft tissue neoplasms with genetic data. Am. J. Surg. Pathol. 2005, 29, 1340-1347. [CrossRef]

34. Kammerer-Jacquet, S.F.; Thierry, S.; Cabillic, F.; Lannes, M.; Burtin, F.; Henno, S.; Dugay, F.; Bouzillé, G.; Rioux-Leclercq, N.; Belaud-Rotureau, M.A.; et al. Differential diagnosis of atypical lipomatous tumor/well-differentiated liposarcoma and dedifferentiated liposarcoma: Utility of p16 in combination with MDM2 and CDK4 immunohistochemistry. Hum. Pathol. 2017, 59, 34-40. [CrossRef] [PubMed]

35. Thway, K.; Flora, R.; Shah, C.; Olmos, D.; Fisher, C. Diagnostic Utility of p16, CDK4, and MDM2 as an Immunohistochemical Panel in Distinguishing Well-differentiated and Dedifferentiated Liposarcomas From Other Adipocytic Tumors. Am. J. Surg. Pathol. 2012, 36, 462-469. [CrossRef] [PubMed]

36. Suster, S.; Fisher, C. Immunoreactivity for the Human Hematopoietic Progenitor Cell Antigen (CD34) in Lipomatous Tumors. Am. J. Surg. Pathol. 1997, 21, 195-200. [CrossRef]

37. Weaver, J.; Downs-Kelly, E.; Goldblum, J.R.; Turner, S.; Kulkarni, S.; Tubbs, R.R.; Rubin, B.P.; Skacel, M. Fluorescence in situ hybridization for MDM2 gene amplification as a diagnostic tool in lipomatous neoplasms. Mod. Pathol. 2008, 21, 943-949. [CrossRef]

38. Kimura, H.; Dobashi, Y.; Nojima, T.; Nakamura, H.; Yamamoto, N.; Tsuchiya, H.; Ikeda, H.; Sawada-Kitamura, S.; Oyama, T.; Ooi, A. Utility of fluorescence in situ hybridization to detect MDM2 amplification in liposarcomas and their morphological mimics. Int. J. Clin. Exp. Pathol. 2013, 15, 1306-1316.

39. Sirvent, N.; Coindre, J.M.; Maire, G.; Hostein, I.; Keslair, F.; Guillou, L.; Ranchere-Vince, D.; Terrier, P.; Pedeutour, F. Detection of MDM2-CDK4 amplification by fluorescence in situ hybridization in 200 paraffin-embedded tumor samples: Utility in diagnosing adipocytic lesions and comparison with immunohistochemistry and real-time PCR. Am. J. Surg. Pathol. 2007, 31, 1476-1489. [CrossRef]

40. Italiano, A.; Bianchini, L.; Gjernes, E.; Keslair, F.; Ranchere-Vince, D.; Dumollard, J.M.; Haudebourg, J.; Leroux, A.; Mainguené, C.; Terrier, P.; et al. Clinical and biological significance of CDK4 amplification in well-differentiated and dedifferentiated liposarcomas. Clin. Cancer Res. 2009, 15, 5696-5703. [CrossRef]

41. Jour, G.; Gullet, A.; Liu, M.; Hoch, B.L. Prognostic relevance of Fédération Nationale des Centres de Lutte Contre le Cancer grade and MDM2 amplification levels in dedifferentiated liposarcoma: A study of 50 cases. Mod. Pathol. 2015, 28, 37-47. [CrossRef] 
42. Ricciotti, R.W.; Baraff, A.J.; Jour, G.; Kyriss, M.; Wu, Y.; Liu, Y.; Li, S.-C.; Hoch, B.; Liu, Y.J. High amplification levels of MDM2 and CDK4 correlate with poor outcome in patients with dedifferentiated liposarcoma: A cytogenomic microarray analysis of 47 cases. Cancer Genet. 2017, 218-219, 69-80. [CrossRef] [PubMed]

43. Lee, S.E.; Kim, Y.J.; Kwon, M.J.; Choi, D.I.; Lee, J.; Cho, J.; Seo, S.W.; Kim, S.J.; Shin, Y.K.; Choi, Y.-L. High level of CDK4 amplification is a poor prognostic factor in well-differentiated and dedifferentiated liposarcoma. Histol. Histopathol. 2013, $29,127-138$.

44. Gronchi, A.; Vullo, S.L.; Fiore, M.; Mussi, C.; Stacchiotti, S.; Collini, P.; Lozza, L.; Pennacchioli, E.; Mariani, L.; Casali, P.G. Aggressive Surgical Policies in a Retrospectively Reviewed Single-Institution Case Series of Retroperitoneal Soft Tissue Sarcoma Patients. J. Clin. Oncol. 2009, 27, 24-30. [CrossRef] [PubMed]

45. Nussbaum, D.P.; Rushing, C.N.; O Lane, W.; Cardona, D.; Kirsch, D.G.; Peterson, B.L.; Blazer, D.G., 3rd. Preoperative or postoperative radiotherapy versus surgery alone for retroperitoneal sarcoma: A case-control, propensity score-matched analysis of a nationwide clinical oncology database. Lancet Oncol. 2016, 17, 966-975. [CrossRef]

46. Haas, R.L.M.; Bonvalot, S.; Miceli, R.; Strauss, D.C.; Swallow, C.J.; Hohenberger, P.; Van Coevorden, F.; Rutkowski, P.; Callegaro, D.; Hayes, A.J.; et al. Radiotherapy for retroperitoneal liposarcoma: A report from the Transatlantic Retroperitoneal Sarcoma Working Group. Cancer 2019, 125, 1290-1300. [CrossRef] [PubMed]

47. Bonvalot, S.; Gronchi, A.; Le Péchoux, C.; Swallow, C.J.; Strauss, D.; Meeus, P.; Van Coevorden, F.; Stoldt, S.; Stoeckle, E.; Rutkowski, P.; et al. Preoperative radiotherapy plus surgery versus surgery alone for patients with primary retroperitoneal sarcoma (EORTC-62092: STRASS): A multicentre, open-label, randomized, phase 3 trial. Lancet Oncol. 2020, 21, 1366-1377. [CrossRef]

48. Bramwell, V.H.; Anderson, D.; Charette, M.L. Doxorubicin-based chemotherapy for the palliative treatment of adult patients with locally advanced or metastatic soft-tissue sarcoma: A meta-analysis and clinical practice guideline. Sarcoma 2000, 4, 103-112. [CrossRef] [PubMed]

49. Gahvari, Z.; Parkes, A. Dedifferentiated liposarcoma: Systemic therapy options. Curr. Treat. Options Oncol. 2020, 21, 15. [CrossRef]

50. Judson, I.; Verweij, J.; Gelderblom, H.; Hartmann, J.T.; Schöffski, P.; Blay, J.-Y.; Kerst, J.M.; Sufliarsky, J.; Whelan, J.; Hohenberger, P.; et al. Doxorubicin alone versus intensified doxorubicin plus ifosfamide for first-line treatment of advanced or metastatic soft-tissue sarcoma: A randomised controlled phase 3 trial. Lancet Oncol. 2014, 15, 415-423. [CrossRef]

51. Ryan, C.W.; Merimsky, O.; Agulnik, M.; Blay, J.-Y.; Schuetze, S.M.; Van Tine, B.A.; Jones, R.L.; Elias, A.D.; Choy, E.; Alcindor, T.; et al. PICASSO III: A Phase III, Placebo-Controlled Study of Doxorubicin With or Without Palifosfamide in Patients With Metastatic Soft Tissue Sarcoma. J. Clin. Oncol. 2016, 34, 3898-3905. [CrossRef]

52. Tap, W.D.; Papai, Z.; Van Tine, B.A.; Attia, S.; Ganjoo, K.N.; Jones, R.L.; Schuetze, S.; Reed, D.; Chawla, S.P.; Riedel, R.F.; et al. Doxorubicin plus evofosfamide versus doxorubicin alone in locally advanced, unresectable or metastatic soft-tissue sarcoma (TH CR-406/SARC021): An international, multicentre, open-label, randomised phase 3 trial. Lancet Oncol. 2017, 18, 1089-1103. [CrossRef]

53. Young, R.J.; Litière, S.; Lia, M.; Hogendoorn, P.C.W.; Fisher, C.; Mechtersheimer, G.; Daugaard, S.; Sciot, R.; Collin, F.; Messiou, C.; et al. Predictive and prognostic factors associated with soft tissue sarcoma response to chemotherapy: A subgroup analysis of the European Organisation for Research and Treatment of Cancer 62012 study. Acta Oncol. 2017, 56, 1013-1020. [CrossRef]

54. Jones, R.L.; Fisher, C.; Al-Muderis, O.; Judson, I.R. Differential sensitivity of liposarcoma subtypes to chemotherapy. Eur. J. Cancer 2005, 41, 2853-2860. [CrossRef] [PubMed]

55. Italiano, A.; Toulmonde, M.; Cioffi, A.; Penel, N.; Isambert, N.; Bompas, E.; Duffaud, F.; Patrikidou, A.; Lortal, B.; Le Cesne, A.; et al. Advanced well-differentiated/dedifferentiated liposarcomas: Role of chemotherapy and survival. Ann. Oncol. 2012, 23, 1601-1607. [CrossRef] [PubMed]

56. Livingston, J.A.; Bugano, D.; Barbo, A.; Lin, H.; Madewell, J.E.; Wang, W.L.; Lazar, A.J.; Tseng, W.W.; Roland, C.L.; Feig, B.W.; et al. Role of chemotherapy in dedifferentiated liposarcoma of the retroperitoneum: Defining the benefit and challenges of the standard. Sci. Rep. 2017, 19, 11836. [CrossRef]

57. Sleijfer, S.; Ray-Coquard, I.; Papai, Z.; Le Cesne, A.; Scurr, M.; Schöffski, P.; Collin, F.; Pandite, L.; Marreaud, S.; De Brauwer, A.; et al. Pazopanib, a multikinase angiogenesis inhibitor, in patients with relapsed or refractory advanced soft tissue sarcoma: A phase II study from the European organisation for research and treatment of cancer-soft tissue and bone sarcoma group (EORTC study 62043). J. Clin. Oncol. 2009, 27, 3126-3132.

58. Van der Graaf, W.T.; Blay, J.-Y.; Chawla, S.P.; Kim, D.-W.; Bui-Nguyen, B.; Casali, P.G.; Schöffski, P.; Aglietta, M.; Staddon, A.P.; Beppu, Y.; et al. Pazopanib for metastatic soft-tissue sarcoma (PALETTE): A randomised, double-blind, placebo-controlled phase 3 trial. Lancet 2012, 379, 1879-1886. [CrossRef]

59. Samuels, B.L.; Chawla, S.P.; Somaiah, N.; Staddon, A.P.; Skubitz, K.M.; Milhem, M.M.; Kaiser, P.E.; Portnoy, D.C.; Priebat, D.A.; Walker, M.S.; et al. Results of a prospective phase 2 study of pazopanib in patients with advanced intermediate-grade or high-grade liposarcoma. Cancer 2017, 123, 4640-4647. [CrossRef]

60. Valverde, C.M.; Martin-Broto, J.; Lopez-Martin, J.A.; Romagosa, C.; Sancho-Marquez, M.P.; Carrasco, J.A.; Poveda, A.; Bauer, S.; Martinez-Trufero, J.; Cruz, J.; et al. Phase II clinical trial evaluating the activity and tolerability of pazopanib in patients (pts) with advanced and/or metastatic liposarcoma (LPS): A joint Spanish Sarcoma Group (GEIS) and German Interdisciplinary Sarcoma Group (GISG) Study-NCT01692496. J. Clin. Oncol. 2016, 34 (Suppl. S15), 11039. [CrossRef] 
61. Grünwald, V.; Kunitz, A.; Schuler, M.K.; Schoffski, P.; Kopp, H.-G.; Bauer, S.; Kasper, B.; Lindner, L.H.; Chemnitz, J.-M.; Crysandt, M.M.; et al. Randomized comparison of pazopanib (PAZ) and doxorubicin (DOX) in the first line treatment of metastatic soft tissue sarcoma (STS) in elderly patients (pts): Results of a phase II study (EPAZ). J. Clin. Oncol. 2018, 36 (Suppl. S15), 11506. [CrossRef]

62. Suehara, Y.; Kohsaka, S.; Yamaguchi, S.; Hayashi, T.; Kurihara, T.; Sano, K.; Sasa, K.; Akaike, K.; Ueno, T.; Kojima, S.; et al. Assessment of Predictive Biomarkers of the Response to Pazopanib Based on an Integrative Analysis of High-grade Soft-tissue Sarcomas: Analysis of a Tumor Sample from a Responder and Patients with Other Soft-tissue Sarcomas. Clin. Orthop. Relat. Res. 2020, 478, 2461-2476. [CrossRef] [PubMed]

63. Mahmood, S.T.; Agresta, S.; Vigil, C.E.; Zhao, X.; Han, G.; D’Amato, G.; Calitri, C.E.; Dean, M.; Garrett, C.; Schell, M.J.; et al. Phase II study of sunitinib malate, a multitargeted tyrosine kinase inhibitor in patients with relapsed or refractory soft tissue sarcomas. Focus on three prevalent histologies: Leiomyosarcoma, liposarcoma and malignant fibrous histiocytoma. Int. J. Cancer 2011, 129, 1963-1969. [CrossRef] [PubMed]

64. Mir, O.; Brodowicz, T.; Italiano, A.; Wallet, J.; Blay, J.-Y.; Bertucci, F.; Chevreau, C.; Piperno-Neumann, S.; Bompas, E.; Salas, S.; et al. Safety and efficacy of regorafenib in patients with advanced soft tissue sarcoma (REGOSARC): A randomised, double-blind, placebo-controlled, phase 2 trial. Lancet Oncol. 2016, 17, 1732-1742. [CrossRef]

65. Chi, Y.; Fang, Z.; Hong, X.-N.; Yao, Y.; Sun, P.; Wang, G.; Du, F.; Sun, Y.; Wu, Q.; Qu, G.; et al. Safety and Efficacy of Anlotinib, a Multikinase Angiogenesis Inhibitor, in Patients with Refractory Metastatic Soft-Tissue Sarcoma. Clin. Cancer Res. 2018, 24, 5233-5238. [CrossRef] [PubMed]

66. Schöffski, P.; Chawla, S.; Maki, R.G.; Italiano, A.; Gelderblom, H.; Choy, E.; Grignani, G.; Camargo, V.; Bauer, S.; Rha, S.Y.; et al. Eribulin versus dacarbazine in previously treated patients with advanced liposarcoma or leiomyosarcoma: A randomised, open-label, multicentre, phase 3 trial. Lancet 2016, 387, 1629-1637. [CrossRef]

67. Demetri, G.D.; Schöffski, P.; Grignani, G.; Blay, J.-Y.; Maki, R.G.; Van Tine, B.A.; Alcindor, T.; Jones, R.L.; D'Adamo, D.R.; Guo, M.; et al. Activity of Eribulin in Patients With Advanced Liposarcoma Demonstrated in a Subgroup Analysis From a Randomized Phase III Study of Eribulin Versus Dacarbazine. J. Clin. Oncol. 2017, 35, 3433-3439. [CrossRef]

68. Demetri, G.D.; Von Mehren, M.; Jones, R.L.; Hensley, M.L.; Schuetze, S.M.; Staddon, A.; Milhem, M.; Elias, A.; Ganjoo, K.; Tawbi, H.; et al. Efficacy and Safety of Trabectedin or Dacarbazine for Metastatic Liposarcoma or Leiomyosarcoma After Failure of Conventional Chemotherapy: Results of a Phase III Randomized Multicenter Clinical Trial. J. Clin. Oncol. $2016,34,786-793$. [CrossRef]

69. Patel, S.; Von Mehren, M.; Reed, D.R.; Kaiser, P.; Charlson, J.; Ryan, C.W.; Rushing, D.; Livingston, M.; Singh, A.; Seth, R.; et al. Overall survival and histology-specific subgroup analyses from a phase 3, randomized controlled study of trabectedin or dacarbazine in patients with advanced liposarcoma or leiomyosarcoma. Cancer 2019, 125, 2610-2620. [CrossRef] [PubMed]

70. Fabbroni, C.; Fucà, G.; Ligorio, F.; Fumagalli, E.; Barisella, M.; Collini, P.; Morosi, C.; Gronchi, A.; Dei Tos, A.P.; Casali, P.G.; et al. Impact of pathological stratification on the clinical outcomes of advanced well-differentiated/dedifferentiated liposarcoma treated with trabectedin. Cancers 2021, 13, 1453. [CrossRef]

71. Maki, R.G. Gemcitabine and docetaxel in metastatic sarcoma: Past, present, and feature. Oncologist 2007, 12, 999-1006. [CrossRef]

72. Maki, R.G.; Wathen, J.K.; Patel, S.R.; Priebat, D.A.; Okuno, S.H.; Samuels, B.; Fanucchi, M.; Harmon, D.C.; Schuetze, S.M.; Reinke, D.; et al. Randomized phase II study of gemcitabine and docetaxel compared with gemcitabine alone in patients with metastatic soft-tissue sarcomas. J. Clin. Oncol. 2007, 25, 2755-2763. [CrossRef]

73. Seddon, B.; Strauss, S.J.; Whelan, J.; Leahy, M.; Woll, P.J.; Cowie, F.; Rothermundt, C.; Wood, Z.; Benson, C.; Ali, N.; et al. Gemcitabine and docetaxel versus doxorubicin as first-line treatment in previously untreated advanced unresectable or metastatic soft-tissue sarcomas (GeDDiS): A randomised controlled phase 3 trial. Lancet Oncol. 2017, 18, 1397-1410. [CrossRef]

74. Bill, K.L.J.; Garnett, J.; Meaux, I.; Ma, X.; Creighton, C.J.; Bolshakov, S.; Barriere, C.; Debussche, L.; Lazar, A.; Prudner, B.C.; et al. SAR405838: A Novel and Potent Inhibitor of the MDM2:p53 Axis for the Treatment of Dedifferentiated Liposarcoma. Clin. Cancer Res. 2016, 22, 1150-1160. [CrossRef]

75. Ray-Coquard, I.; Blay, J.Y.; Italiano, A.; Le Cesne, A.; Penel, N.; Zhi, J.; Heil, F.; Rueger, R.; Graves, B.; Ding, M.; et al. Effect of the MDM2 antagonist RG7112 on the P53 pathway in patients with MDM2-amplified, well-differentiated or dedifferentiated liposarcoma: An exploratory proof-of-mechanism study. Lancet Oncol. 2012, 13, 1133-1140. [CrossRef]

76. De Jonge, M.; de Weger, V.A.; Dickson, M.A.; Langenberg, M.; Le Cesne, A.; Wagner, A.J.; Hsu, K.; Zheng, W.; Macé, S.; Tuffal, G.; et al. A phase I study of SAR405838, a novel human double minute 2 (HDM2) antagonist, in patients with solid tumours. Eur. J. Cancer 2017, 76, 144-151. [CrossRef]

77. Wagner, A.J.; Banerji, U.; Mahipal, A.; Somaiah, N.; Hirsch, H.; Fancourt, C.; Johnson-Levonas, A.O.; Lam, R.; Meister, A.K.; Russo, G.; et al. Phase I Trial of the Human Double Minute 2 Inhibitor MK-8242 in Patients With Advanced Solid Tumors. J. Clin. Oncol. 2017, 35, 1304-1311. [CrossRef]

78. Bauer, T.M.; Gounder, M.M.; Weise, A.M.; Schwartz, G.K.; Carvajal, R.D.; Kumar, P.; Zernovak, O.; Beck, A.; Doyle, J.; Mendell-Harary, J.; et al. A phase 1 study of MDM2 inhibitor DS-3032b in patients with well/de-differentiated liposarcoma (WD/DD LPS), solid tumors (ST) and lymphomas (L). J. Clin. Oncol. 2018, 36 (Suppl. S15), 11514. [CrossRef]

79. Jung, J.; Lee, J.S.; Dickson, M.A.; Schwartz, G.K.; Le Cesne, A.; Varga, A.; Bahleda, R.; Wagner, A.J.; Choy, E.; De Jonge, M.J.; et al. TP53 mutations emerge with HDM2 inhibitor SAR405838 treatment in de-differentiated liposarcoma. Nat. Commun. 2016, 7, 12609. [CrossRef] [PubMed] 
80. Dickson, M.A.; Schwartz, G.K.; Keohan, M.L.; D'Angelo, S.P.; Gounder, M.M.; Chi, P.; Antonescu, C.R.; Landa, J.; Qin, L.X.; Crago, A.M.; et al. Progression-free survival among patients with well-differentiated or dedifferentiated liposarcoma treated with CDK4 inhibitor palbociclib: A phase 2 clinical trial. JAMA Oncol. 2016, 2, 937-940. [CrossRef]

81. Infante, J.R.; Cassier, P.A.; Gerecitano, J.F.; Witteveen, P.O.; Chugh, R.; Ribrag, V.; Chakraborty, A.; Matano, A.; Dobson, J.R.; Crystal, A.S.; et al. A phase I study of the cyclin-dependent kinase 4/6 inhibitor ribociclib (LEE011) in patients with advanced solid tumors and lymphomas. Clin. Cancer Res. 2016, 22, 5696-5705. [CrossRef] [PubMed]

82. Dickson, M.A.; Koff, A.; D'Angelo, S.P.; Gounder, M.M.; Keohan, M.L.; Kelly, C.M.; Chi, P.; Antonescu, C.R.; Landa, J.; Qin, L.X.; et al. Phase 2 study of the CDK4 inhibitor abemaciclib in dedifferentiated liposarcoma. J. Clin. Oncol. 2019, 37 (Suppl. S15), 11004. [CrossRef]

83. Laroche-Clary, A.; Chaire, V.; Algeo, M.P.; Derieppe, M.A.; Loarer, F.L.; Italiano, A. Combined targeting of MDM2 and CDK4 is synergistic in dedifferentiated liposarcomas. J. Hematol. Oncol. 2017, 10, 123. [CrossRef] [PubMed]

84. Garg, M.; Kanojia, D.; Mayakonda, A.; Said, J.W.; Doan, N.B.; Chien, W.; Ganesan, T.S.; Chuang, L.S.; Venkatachalam, N.; Baloglu, E.; et al. Molecular mechanism and therapeutic implications of selinexor (KPT-330) in liposarcoma. Oncotarget 2017, 8, 7521-7532. [CrossRef] [PubMed]

85. Zuco, V.; Pasquali, S.; Tortoreto, M.; Brich, S.; Percio, S.; Dagrada, G.P.; Colombo, C.; Sanfilippo, R.; Lauricella, C.; Gounder, M.; et al. Selinexor versus doxorubicin in dedifferentiated liposarcoma PDXs: Evidence of greater activity and apoptotic response dependent on p53 nuclear accumulation and surviving down-regulation. J. Exp. Clin. Cancer Res. 2021, 40, 83. [CrossRef]

86. Gounder, M.M.; Zer, A.; Tap, W.D.; Salah, S.; Dickson, M.A.; Gupta, A.A.; Keohan, M.L.; Loong, H.; D'Angelo, S.P.; Baker, S.; et al. Phase IB Study of Selinexor, a First-in-Class Inhibitor of Nuclear Export, in Patients With Advanced Refractory Bone or Soft Tissue Sarcoma. J. Clin. Oncol. 2016, 34, 3166-3174. [CrossRef]

87. Gounder, M.; Razak, A.A.; Somaiah, N.; Martin-Broto, J.; Schuetze, S.; Grignani, G.; Chawla, S.P.; Chmielowski, B.; Vincenzi, B.; Stacchiotti, S.; et al. A phase 2/3, randomized, double-Blind, cross-over study of selinexor versus placebo in advanced unresectable dedifferentiated liposarcoma (DDLS). In Proceedings of the Connective Tissue Oncology Society (CTOS) Virtual Annual Meeting, Online, 18-21 November 2020.

88. Gounder, M.; Razak, A.R.A.; Gilligan, A.M.; Leong, H.; Ma, X.; Somaiah, N.; Chawla, S.P.; Martin-Broto, J.; Grignani, G.; Schuetze, S.M.; et al. Health-related quality of life and pain with selinexor in patients with advanced dedifferentiated liposarcoma. Futur. Oncol. 2021. [CrossRef]

89. Wisdom, A.J.; Mowery, Y.M.; Riedel, R.F.; Kirsch, D.G. Rationale and emerging strategies for immune checkpoint blockade in soft tissue sarcoma. Cancer 2018, 124, 3819-3829. [CrossRef]

90. Park, H.K.; Kim, M.; Sung, M.; Lee, S.E.; Kim, Y.J.; Choi, Y.-L. Status of programmed death-ligand 1 expression in sarcomas. J. Transl. Med. 2018, 16, 303. [CrossRef]

91. Vargas, A.C.; MacLean, F.M.; Sioson, L.; Tran, D.; Bonar, F.; Mahar, A.; Cheah, A.L.; Russell, P.; Grimison, P.; Richardson, L.; et al. Prevalence of PD-L1 expression in matched recurrent and/or metastatic sarcoma samples and in a range of selected sarcomas subtypes. PLoS ONE 2020, 15, e0222551. [CrossRef] [PubMed]

92. Miyake, M.; Oda, Y.; Nishimura, N.; Morizawa, Y.; Ohnishi, S.; Hatakeyama, K.; Fujii, T.; Hori, S.; Gotoh, D.; Nakai, Y.; et al. Integrative assessment of clinicopathological parameters and the expression of PD-L1, PD-L2 and PD-1 in tumor cells of retroperitoneal sarcoma. Oncol. Lett. 2020, 20, 1. [CrossRef] [PubMed]

93. A Tawbi, H.; Burgess, M.; Bolejack, V.; A Van Tine, B.; Schuetze, S.M.; Hu, J.; D'Angelo, S.; Attia, S.; Riedel, R.F.; A Priebat, D.; et al. Pembrolizumab in advanced soft-tissue sarcoma and bone sarcoma (SARC028): A multicentre, two-cohort, single-arm, open-label, phase 2 trial. Lancet Oncol. 2017, 18, 1493-1501. [CrossRef]

94. Burgess, M.A.; Bolejack, V.; Schuetze, S.; Van Tine, B.A.; Attia, S.; Riedel, R.F.; Hu, J.S.; Daivs, L.E.; Okuno, S.H.; Priebat, D.A.; et al. Clinical activity of pembrolizumab (P) in undifferentiated pleomorphic sarcoma (UPS) and dedifferentiated/pleomorphic liposarcoma (LPS): Final results of SARC028 expansion cohorts. J. Clin. Oncol. 2019, 37 (Suppl. S15), 11015. [CrossRef]

95. D'Angelo, S.P.; Mahoney, M.R.; A Van Tine, B.; Atkins, J.; Milhem, M.; Jahagirdar, B.N.; Antonescu, C.R.; Horvath, E.H.; Tap, W.D.; Schwartz, G.K.; et al. Nivolumab with or without ipilimumab treatment for metastatic sarcoma (Alliance A091401): Two open-label, non-comparative, randomised, phase 2 trials. Lancet Oncol. 2018, 19, 416-426. [CrossRef]

96. Chen, J.L.; Mahoney, M.R.; George, S.; Antonescu, C.R.; Liebner, D.A.; Van Tine, B.A.; Milhem, M.M.; Tap, W.D.; Streicher, H.; Schwartz, G.K.; et al. A multicenter phase II study of nivolumab + / - ipilimumab for patients with metastatic sarcoma (Alliance A091401): Results of expansion cohorts. J. Clin. Oncol. 2020, 38 (Suppl. S15), 11511. [CrossRef]

97. Keung, E.Z.; Lazar, A.J.; E Torres, K.; Wang, W.-L.; Cormier, J.N.; Guadagnolo, B.A.; Bishop, A.; Lin, H.; Hunt, K.K.; Bird, J.; et al. Phase II study of neoadjuvant checkpoint blockade in patients with surgically resectable undifferentiated pleomorphic sarcoma and dedifferentiated liposarcoma. BMC Cancer 2018, 18, 913. [CrossRef] [PubMed]

98. Roland, C.L.; Keung, E.Z.; Lazar, A.J.; Torres, K.E.; Wang, W.L.; Ashleigh Guadagnolo, B.; Bishop, A.J.; Lin, H.Y.; Hunt, K.; Feig, B.W.; et al. Preliminary results of a phase II study of neoadjuvant checkpoint blockade for surgically resectable undifferentiated pleomorphic sarcoma (UPS) and dedifferentiated liposarcoma (DDLPS). J. Clin. Oncol. 2020, 38 (Suppl. S15), 11505. [CrossRef]

99. Mowery, Y.M.; Ballman, K.V.; Riedel, R.F.; Brigman, B.E.; Attia, S.; Meyer, C.F.; Schuetze, S.; Burgess, M.A.; Chmielowski, B.; Dickson, M.A.; et al. SU2C-SARC032: A phase II randomized controlled trial of neoadjuvant pembrolizumab with radiotherapy and adjuvant pembrolizumab for high-risk soft tissue sarcoma. J. Clin. Oncol. 2018, 36 (Suppl. S15), 11588. [CrossRef] 